\title{
Small-bowel perforation after endoscopic resection of a Peutz-Jeghers polyp in an infant using double- balloon enteroscopy
}

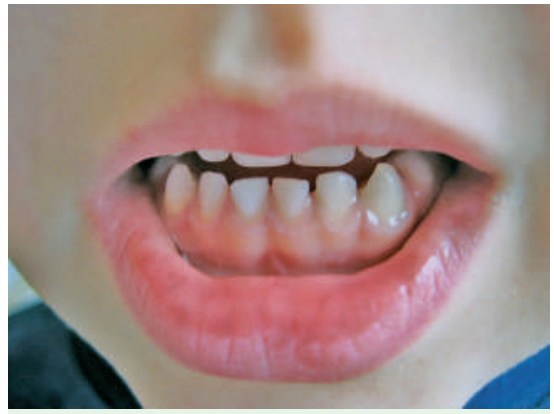

Figure 1 The characteristic mucocutaneous macules of Peutz-Jeghers syndrome located on the lower lip of the patient.

Double-balloon-enteroscopy (DBE) provides a facility for the diagnosis and treatment of small-intestinal disease [1]. To date its use has not been described in infants. A boy aged 3 years and 10 months who had small-intestinal bleeding underwent esophagogastroduodenoscopy in another hospital, when two gastric polyps were found. He was referred to us for DBE. Peutz-Jeghers syndrome was diagnosed on the basis of the findings of gastric polyps and circumoral pigmentation ( $\bullet$ Figure 1). DBE was performed after informed consent was obtained, using a Fujinon EN-450 P5/20 endoscope (FujinonToshiba ES System Co. Ltd., Tokyo, Japan) under general anesthesia. A large polyp $(3 \mathrm{~cm})$ was found in the proximal jejunum, which had surface erosions ( $\bullet$ Figure $\mathbf{2} \mathbf{a}$ ). The polyp was removed using a diathermy loop. Histological examination confirmed the diagnosis of a Peutz-Jeghers polyp ( $\bullet$ Figure $\mathbf{2 b}$ ). There were erosions within the polyp ( $\bullet$ Figure $2 \mathrm{c}$ ), suggesting a possible source of bleeding. A double-balloon colonoscopy performed subsequently was unremarkable, but ileoscopy was not possible.

A second DBE was performed 18 days later because of hematochezia. No source of bleeding could be detected, but a perforation was seen in the proximal jejunum while withdrawing the endoscope. At laparotomy, the perforation was found to be attached to an adhesion that was extending from the distal ileum to the site of the former jejunal polyp. The perforated segment was resected. On examina-

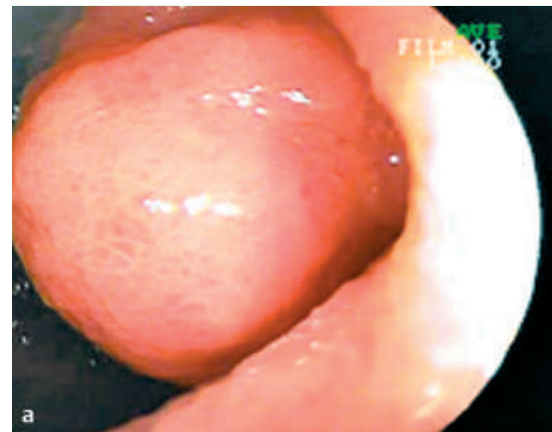

mural intestinal injury had taken place during the resection of the jejunal polyp. The push and pull forces between parts of the small intestine were probably transmitted to the adhesion during the second DBE, leading to perforation. The potential benefits of DBE, combined with the facility for endoscopic resection of intestinal polyps [2] have to be balanced against the increased risk of perforation in infants.

Endoscopy_UCTN_Code_CPL_1AI_2AC

T. W. Spahn ${ }^{1}$, W. Kampmann², M. Eilers ${ }^{2}$, M. K. Mueller ${ }^{1}$, B. Rodeck ${ }^{2}$

${ }^{1}$ Department of General Internal Medicine and Gastroenterology, Marienhospital Osnabrueck, Academic Teaching Hospital of the Hannover Medical School, Osnabrueck, Germany

2 Department of Pediatrics and Juvenile Medicine, Marienhospital Osnabrueck, Academic Teaching Hospital of the Hannover Medical School, Osnabrueck, Germany

\section{References}

1 Yamamoto H, Yano T, Kita $H$ et al. New system of double-balloon enteroscopy for diagnosis and treatment of small intestinal disorders. Gastroenterology 2003; 125: 1556 [author reply 1556 - 1557]

2 Ohmiya N, Taguchi A, Shirai K et al. Endoscopic resection of Peutz-Jeghers polyps throughout the small intestine at doubleballoon enteroscopy without laparotomy. Gastrointest Endosc 2005; 61: 140 - 147

Bibliography

DOI 10.1055/s-2007-966411

Endoscopy 2007; 39: E217

(c) Georg Thieme Verlag KG Stuttgart · New York . ISSN 0013-726X

Corresponding author

\section{B. Rodeck, MD}

Department of Pediatric and Juvenile Medicine Marienhospital Osnabrueck

Academic Teaching Hospital of the Hannover Medical School

Johannisfreiheit 2-4

D-49074 Osnabrueck

Germany

Fax: +49-541-326-4560

burkhard.rodeck@mho.de 